\title{
RESEARCH
}

\section{The androgen receptor in bone marrow progenitor cells negatively regulates fat mass}

\author{
Patricia K Russell1, Salvatore Mangiafico', Barbara C Fam1, Michele V Clarke', Evelyn S Marin', \\ Sofianos Andrikopoulos', Kristine M Wiren'², Jeffrey D Zajac' and Rachel A Davey ${ }^{1}$ \\ 1Department of Medicine, Austin Health, University of Melbourne, Heidelberg, Victoria, Australia \\ 2Research Service, Veterans Affairs Medical Center, Portland, Oregon, USA \\ ${ }^{3}$ Departments of Medicine and Behavioral Neuroscience, Oregon Health \& Science University, Portland, Oregon, USA \\ Correspondence should be addressed to R A Davey: r.davey@unimelb.edu.au
}

\section{Abstract}

It is well established that testosterone negatively regulates fat mass in humans and mice; however, the mechanism by which testosterone exerts these effects is poorly understood. We and others have shown that deletion of the androgen receptor (AR) in male mice results in a phenotype that mimics the three key clinical aspects of hypogonadism in human males; increased fat mass and decreased bone and muscle mass. We now show that replacement of the Ar gene specifically in mesenchymal progenitor cells (PCS) residing in the bone marrow of Global-ARKO mice, in the absence of the AR in all other tissues (PC-AR Gene Replacements), completely attenuates their increased fat accumulation. Inguinal subcutaneous white adipose tissue and intra-abdominal retroperitoneal visceral adipose tissue depots in PC-AR Gene Replacement mice were 50-80\% lower than wild-type (WT) and 75-90\% lower than Global-ARKO controls at 12 weeks of age. The marked decrease in subcutaneous and visceral fat mass in PC-AR Gene Replacements was associated with an increase in the number of small adipocytes and a healthier metabolic profile compared to WT controls, characterised by normal serum leptin and elevated serum adiponectin levels. Euglycaemic/hyperinsulinaemic clamp studies reveal that the PC-AR Gene Replacement mice have improved whole-body insulin sensitivity with higher glucose infusion rates compared to WT mice and increased glucose uptake into subcutaneous and intra-abdominal fat. In conclusion, these data provide the first evidence for an action of androgens via the AR in mesenchymal bone marrow PCs to negatively regulate fat mass and improve metabolic function.

\author{
Key Words \\ - testosterone \\ - androgen receptor \\ - adipose tissue \\ - glucose metabolism \\ - androgen
}

\section{Introduction}

There are abundant data that fat mass is negatively regulated by androgens in men. Hypogonadal men with low serum testosterone levels have increased visceral obesity compared to men with normal serum testosterone (Bhasin et al. 1997, Hamilton et al. 2011). Conversely, testosterone treatment decreases fat mass, not only in hypogonadal men (Wang et al. 2000), but also in men with normal testosterone levels (Bhasin et al. 2001) and in female-to-male transgender patients (Van Caenegem et al. 2015). Although these combined reports indicate that testosterone is a major negative regulator of fat accumulation, little is known about the mechanism by which testosterone exerts this action. 
Studying the in vivo actions of androgens is complex as testosterone can be aromatised to oestradiol or metabolised to dihydrotestosterone (DHT). Genetically modified animals have proven to be excellent model systems to dissect the contribution of androgens in the regulation of bone and body composition with many aspects of the regulation of these tissues being shared between mice and humans. We, and others, have shown in mice that the actions of testosterone to decrease fat mass are mediated via the androgen receptor (AR). An in-frame deletion of exon 3 of the AR in our Global-ARKO mice $\left(\mathrm{AR}^{\triangle \mathrm{ZF} 2}\right)$ abolishes the DNA-binding-dependent actions of the AR, whilst the non-DNA-binding-dependent actions remain functional (Notini et al. 2005, Pang et al. 2012). These Global-ARKO mice exhibit a phenotype that mimics the three key clinical aspects of hypogonadism in human males, that is increased fat mass, as well as decreased bone and muscle mass (MacLean et al. 2008, 2010, Rana et al. 2011). The increased visceral and subcutaneous fat pad mass in Global-ARKOs is characterised by an increase in the number of large adipocytes, as well as increased serum leptin and adiponectin levels and decreased voluntary activity in the absence of insulin resistance (Rana et al. 2011). Similar observations of increased fat mass have been reported in two other complete AR-null mouse models with the exception that these male AR-null mice develop late-onset obesity characterised by hyperinsulinaemia, hyperglycaemia and hyperleptinaemia (Lin et al. 2005) or increased serum adiponectin and altered energy balance in the absence of any changes in insulin sensitivity (Fan et al. 2005). It is possible that the differences in the metabolic phenotype between the different mouse models is due to the influence of genetic background (Davey \& MacLean 2006) as these AR-null models were on a mixed genetic background (Fan et al. 2005, Lin et al. 2005) or may also reflect a physiological role of the non-genomic actions of the AR in fat metabolism, which are retained in our Global-ARKO mice (Pang et al. 2012). More recently, it has been shown in a different AR-null mouse model, that absence of the AR confers an increased susceptibility to high fat feeding-induced adiposity and glucose tolerance (Dubois et al. 2016). Together, these data support an important action of androgens via the AR to regulate fat mass accumulation.

Further insight into the role of androgens via the AR in regulating fat mass accumulation and metabolism has been provided by mouse models in which the AR has been deleted specifically in adipocytes (Yu et al. 2008, McInnes et al. 2012). In contrast to the Global- and null-AR mouse models, male adipocyte-ARKO mice do not exhibit increased fat mass and do not develop late-onset obesity. However, deletion of the AR in adipocytes in male mice using AP2-Cre mice has been reported to lead to increased serum leptin (Yu et al. 2008), whilst in other adipocyteARKO mouse models generated using either AP2-Cre or adiponectin-Cre mice, results in an initial phenotype of hyperinsulinaemia, followed by insulin deficiency a year later (McInnes et al. 2012). Together, these data suggest a possible role for AR signalling in adipose tissue to regulate leptin expression and insulin action independent of adiposity. Importantly, the absence of increased fat mass in the different adipocyte-ARKO mouse models suggests that the major target of androgen action to regulate subcutaneous and visceral fat accumulation is mediated via the $\mathrm{AR}$ in another target tissue.

Evidence exists showing that fat, bone and muscle engage in cross-talk both systemically and within their local microenvironment (Ilich et al. 2014). This includes (1) endocrine regulation via the secretion of regulatory factors from bone, fat and muscle (i.e. osteokines, adipokines and myokines respectively) into the systemic circulation and (2) regulation of the commitment of mesenchymal progenitor cells (PCs) into the osteoblastogenic, adipogenic or myogenic lineage. The first osteokine identified to regulate energy metabolism was osteocalcin, a bone-specific glycoprotein synthesised by mineralising osteoblasts within bone. Following its release into the circulation, target tissues of osteocalcin include the pancreas, liver, white adipose tissue (WAT), brown adipose tissue (BAT) and muscle, where it regulates glucose and energy homeostasis by acting on beta cell proliferation, insulin production, insulin sensitivity and energy expenditure (Lee \& Karsenty 2008). Given the complex and interconnected nature of bone and energy metabolism, it is highly conceivable that there are other, yet unidentified feedback pathways in bone tissue that regulate energy metabolism that are also influenced by hormones, such as testosterone.

In the development of obesity, the increase in fat mass is due to an increase in the number of large adipocytes (Jo et al. 2009). This occurs via recruitment of pre-adipocytes from subpopulations of cells resident within mature WAT (Rodeheffer et al. 2008). There is also evidence to suggest that pre-adipocytes can be recruited from the bone marrow (Crossno et al. 2006). Data obtained from in vitro experiments show that testosterone can inhibit the differentiation of human and mouse bone marrow mesenchymal PCs into adipocytes via an AR-dependent pathway (Gupta et al. 2008, Huang et al. 2013) and is able to prevent rosiglitazone-induced adipogenesis 
whilst promoting osteogenesis in human bone marrow PCs (Benvenuti et al. 2012). Whether the actions of testosterone to negatively regulate fat accumulation are mediated via the AR in bone marrow PCs to divert their differentiation away from adipocytes remains an area of debate as the migration of mesenchymal PCs from the bone marrow into peripheral tissues, such as fat, is extremely low (Tomiyama et al. 2008). In fact, the bone marrow-derived adipocytes found in fat tissue are most likely from haematopoietic rather than mesenchymal origin (Majka et al. 2010).

Therefore, in order to determine whether androgens can act in mesenchymal PCs residing in the bone marrow to influence fat deposition and metabolism in male mice in vivo, we generated a genetically modified mouse model in which the AR gene is replaced specifically in bone marrow mesenchymal PCs of Global-ARKO mice (PC-AR Gene Replacements) (Russell et al. 2015). These mesenchymal PCs are pluripotent and can differentiate into osteoprogenitors, osteoblast and osteocytes as well as adipocytes, chondrocytes and myoblasts. The strength of this unique PC-AR Gene Replacement model is the selective targeting of androgen signalling via expression of the AR specifically in PCs residing in the bone marrow with the AR remaining deleted in all other tissues. As such, this PC-AR Gene Replacement model is a powerful tool that has allowed us to identify and define the specific actions of the AR in bone marrow PCs that mediate fat mass accumulation and influence body composition without the influence of AR action in other tissues.

\section{Materials and methods}

\section{Generation of bone marrow progenitor cell-AR Gene Replacement mice}

The generation of the $\mathrm{AR}^{\triangle \mathrm{ZF} 2}$ (Global-ARKO) mice used in this study has been described previously (Notini et al. 2005, Pang et al. 2012). PC-AR Gene Replacement and mOBL-AR Gene Replacement male mice where the AR was replaced only in (a) PCs residing in the bone marrow and osteoprogenitors or in (b) mature osteoblasts of Global-ARKOs respectively, were generated by breeding heterozygous female Global-ARKO mice with (a) heterozygous male Col3.6AR-tg mice (Wiren et al. 2008, Semirale et al. 2011) or (b) heterozygous Col2.3AR-tg mice (Wiren et al. 2008). A unique feature of the PC-AR and mOBL-AR Gene Replacement mice is that as they inherit the $\mathrm{X}$ chromosome (on which the mutant AR is located) from their Global-ARKO mother, they do not express endogenous AR in any tissue. All mice used in the study were on a congenic C57BL6/J background. Wild-type (WT) and Global-ARKO littermate controls were included in all analyses ( $n=8-15$ per group). The PCR protocols used for genotyping the WT, Global-ARKO, PC-AR and mOBL-AR Gene Replacement mice have been described previously (Russell et al. 2015).

\section{Animal husbandry and housing}

Mice were housed in a specified pathogen-free (SPF) facility and supplied with sterile autoclaved water and standard irradiated mouse chow containing 1.2\% calcium, $0.96 \%$ phosphorous, $9 \%$ fat and $22 \%$ protein (Ridley Agriproducts, Corowa, NSW, Australia) ad libitum and were housed at $22^{\circ} \mathrm{C}$ in a 12 -h light/darkness cycle. All procedures were approved by the Austin Health Animal Ethics Committee (A2014/05188).

\section{Tissue collection and serum analysis}

PC-AR Gene Replacement mice were studied at 6 and 12 weeks of age and mOBL-AR Gene Replacement mice were studied at 12 weeks of age. Mice were anaesthetized by intraperitoneal injection of $110 \mathrm{mg} / \mathrm{kg}$ ketamine and $10 \mathrm{mg} / \mathrm{kg}$ xylazine, blood collected via cardiac puncture followed by cervical dislocation and tissues were collected.

\section{Metabolic analyses}

Food intake and voluntary physical activity were measured at 12 weeks of age and fasting energy expenditure was measured at 6 and 12 weeks of age as previously described (Cui et al. 2015, Fam et al. 2015). Briefly, food intake was determined in mice that were housed separately by weighing food each morning over a seven-day period and daily food intake averaged over the seven days. Voluntary activity was measured by monitoring the use of running wheels with a computerised metre (Fam et al. 2015) and fasting energy expenditure was determined by measuring the body weight of the mice prior to and following an overnight fast of $16 \mathrm{~h}$ and calculated as the change in body weight (Cui et al. 2015).

\section{Biochemical analyses}

Serum adiponectin, insulin and leptin were determined by ELISA (R\&D Systems; Alpco, Salem, NH, USA and Millipore respectively). All ELISAs were performed according to 
the manufacturer's instructions using the online data analysis tool MyAssays Ltd. (http://www.myassays.com; 5th December 2014, East Sussex, UK). Serum glucose was analysed using the GM7 MicroStat (Analox instruments, Stourbridge, UK). Serum levels of non-esterified fatty acid (NEFA), triglycerides and glycerol were measured using commercially available assays (Wako; Sigma-Aldrich).

\section{Adipocyte histology}

Subcutaneous WAT, retroperitoneal VAT depots and left femora were fixed in 4\% paraformaldehyde in PBS, with the femora undergoing decalcification in 15\% EDTA in $0.5 \%$ paraformaldehyde/PBS, pH 8.0 for 6 days. Tissues were embedded in paraffin and $5 \mu \mathrm{m}$ cross-sections and midsagittal sections cut for fat tissue and femora respectively. For WAT and VAT depots, four fields were randomly selected from each section at $\times 200$ magnification for each animal, representing $>300$ adipocytes for WT controls. For femora, a region representing the mid-femur commencing $2 \mathrm{~mm}$ distal of the growth plate and extending $4 \mathrm{~mm}$ distally was analysed at $\times 100$ magnification. The number, density and cross-sectional area of adipocytes were analysed using the Osteomeasure system (Osteometrics, Atlanta, GA, USA). All analyses were performed in a blinded fashion.

\section{Quantitative real-time PCR (Q-PCR)}

RNA was extracted from one entire fat pad collected from each subcutaneous WAT, retroperitoneal VAT and BAT depot for each mouse and in whole bone RNA samples of WT, Global-ARKO and PC-AR Gene Replacements ( $n=10-13$ per group), and cDNA synthesis was performed as described previously (Russell et al. 2015). For quantifying absolute endogenous and transgene AR mRNA expression in the fat depots, 4 samples/genotype were run against a standard curve consisting of 8 data points ranging from 0 to $500 \mathrm{ng}$ performed in duplicate using an Applied Biosystems TaqMan gene expression assay for exon 3 of the AR (Supplementary Table 1, see section on supplementary data given at the end of this article) and an Applied Biosystems 7500 Real-Time PCR System. Relative expression of the mRNA levels of all other genes of interest in fat depots and whole bone were determined by Q-PCR using Applied Biosystems TaqMan gene expression assays (Supplementary Table 1) as described (Russell et al. 2012). Relative expression was calculated using the $\Delta \Delta \mathrm{CT}$ method with values for the gene of interest normalised to Hmbs in bone, which is stably expressed in both osteoclasts and osteoblasts (Stephens et al. 2011) and Eef2 in fat, which is constantly expressed in adipose tissue and unaffected by gonadectomy in mice, (Kouadjo et al. 2007) and expressed relative to a reference sample.

\section{Euglycaemic/hyperinsulinaemic clamp studies}

Hyperinsulinaemic-euglycaemic clamps were performed in 4-h-fasted mice as previously described (Lamont et al. 2006). In the current study, an initial 2-min-priming dose of insulin $(150 \mathrm{mU} / \mathrm{kg} / \mathrm{min})$ was followed by constant infusion at a rate of $15 \mathrm{mU} / \mathrm{kg} / \mathrm{min}$. Euglycaemia was maintained by variable infusion of $12.5 \%$ glucose solution in $0.9 \%$ saline. Glucose turnover was calculated using Steele's steady state equation and glucose uptake into individual tissues determined (Lamont et al. 2006).

\section{Statistical analyses}

Statistically significant differences between PC-AR Gene Replacements or mOBL-AR Gene Replacements and littermate controls (WT and Global-ARKOs) were identified by one-way ANOVA with specific differences identified by Tukey's or Tamhane's post hoc tests for equal and unequal variance respectively as indicated by Levene's test of homogeneity. Since changes in body weight can indirectly account for changes in fat mass, analysis of covariance (ANCOVA) was used to determine the influence of genotype on the weight of specific fat depots after controlling for body weight. All data were analysed with SPSS for MacOSX. A two-tailed $P$ value of $<0.05$ was considered significant. Data are presented as mean \pm standard error of the mean (s.e.).

\section{Results}

\section{Ar gene expression in PC-AR Gene Replacement males}

To investigate whether androgen signalling via the AR in bone marrow mesenchymal PCs can influence fat deposition in male mice in vivo, we replaced the $A r$ gene specifically in bone marrow mesenchymal PCs of GlobalARKO mice. We have previously reported that the level of Ar transgene expression in whole bone, including bone marrow PCs of PC-AR Gene Replacement mice is at the same level observed in WT, and endogenous $A r$ gene expression is undetectable in Global-ARKO and PC-AR Gene Replacement mice (Russell et al. 2015). Importantly, Ar gene expression is undetectable in inguinal subcutaneous WAT, intra-abdominal retroperitoneal VAT 
and BAT depots of PC-AR Gene Replacements (Fig. 1). We have previously reported, whilst not statistically significant, the mean values of serum testosterone in PC-AR Gene Replacements and Global-ARKOs are lower than WT (Russell et al. 2015), consistent with our previous report in male Global-ARKOs (Notini et al. 2005).

\section{Subcutaneous WAT and retroperitoneal VAT mass in PC-AR Gene Replacement males}

We have previously shown that Global-ARKO males have increased subcutaneous WAT and retroperitoneal VAT mass (Rana et al. 2011). We now show that replacement of $A r$ gene expression in bone marrow PCs of Global-ARKO mice completely attenuated their increased fat mass, resetting subcutaneous WAT and retroperitoneal VAT depots of PC-AR Gene Replacement mice to $52 \%$ and $83 \%$ lower than the normal levels observed in WT littermates respectively, by 12 weeks of age $(P<0.001)$ (Fig. $2 \mathrm{~A}$ and $B)$. Not surprisingly, the marked decrease in fat mass in PC-AR Gene Replacement mice resulted in a decrease in body weight compared to both WT and Global-ARKO controls (Table 1). Importantly, ANCOVA analysis showed that the decrease in fat mass in PC-AR Gene Replacements remained statistically significant after correction for body weight with genotype accounting for $70 \%(P<0.001)$ and $55 \%(P<0.001)$ of the effects observed on subcutaneous WAT and retroperitoneal VAT respectively, at 12 weeks of age. The reduction in WAT and VAT fat mass in the PC-AR Gene Replacement mice occurred in the absence

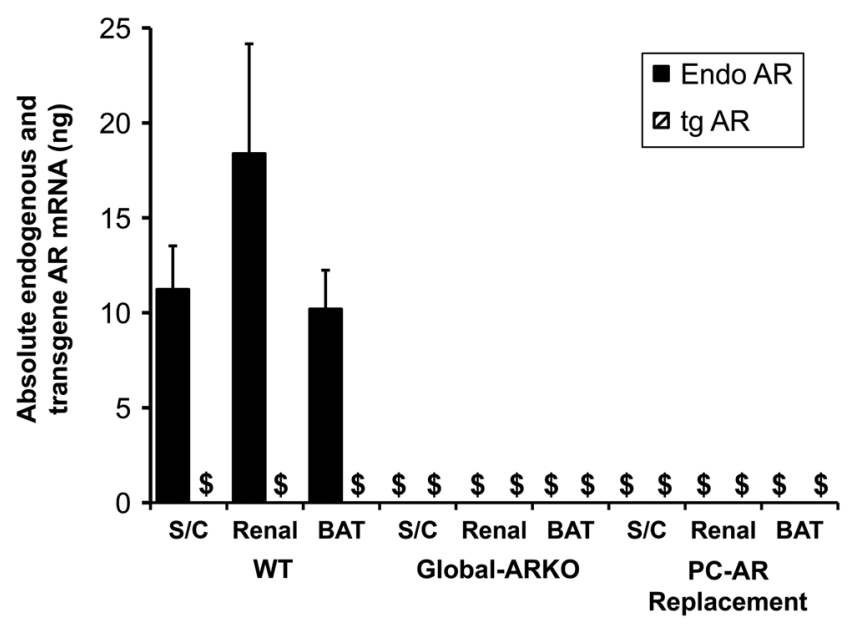

Figure 1

Endogenous AR (endo) and AR transgene (tg) mRNA in subcutaneous (S/C), peri-renal and brown adipose tissue (BAT) of wild-type (WT), Global-ARKO and PC-AR Gene Replacements males at 12 weeks of age by Q-PCR. Values are mean +S.E., $n=4-5 /$ group, $\$$ - denotes undetectable levels of mRNA.

(C) 2018 Society for Endocrinology Published by Bioscientifica Ltd. Printed in Great Britain of any change in food consumption, energy expenditure or voluntary activity compared to Global-ARKO controls (Table 1). Since the AR in the PC-AR Gene Replacements has been replaced in bone marrow PCs, the AR will also be replaced in the differentiated descendants of these PCs including mature osteoblasts, mineralising osteoblasts and osteocytes. Therefore, in order to determine whether this action of androgens via the AR to decrease subcutaneous WAT and retroperitoneal VAT accumulation was attributed to an action in bone marrow PCs and osteoprogenitors as opposed to a more mature population of osteoblasts and osteocytes, we assessed the fat depots in Global-ARKO mice in which the AR was specifically replaced from the mature stage of osteoblast development (mOBL-AR Gene Replacements). Subcutaneous WAT and retroperitoneal VAT mass of mOBL-AR Gene Replacement mice did not differ from WT controls at 12 weeks of age (Supplementary Table 2), indicating that the action of the AR in the PC-AR Gene Replacement mice to decrease WAT, and VAT accumulation is mediated at an earlier stage of osteoblast development, in bone marrow mesenchymal PCs and osteoprogenitors. As such, we focussed our studies to characterise the metabolic phenotype of the PC-AR Gene Replacement mice.

\section{Adipocyte histology and serum biochemistry of PC-AR Gene Replacement males}

The marked decrease in subcutaneous WAT and retroperitoneal VAT mass in PC-AR Gene Replacement males was associated with a shift in the distribution of adipocyte cross-sectional area with an increase in the number of small adipocytes compared to WT and GlobalARKOs (Fig. 2C and D). Consistent with our previous observations (Rana et al. 2011), Global-ARKOs had elevated serum levels of leptin $(P<0.05)$ and adiponectin $(P<0.001)$ compared to WT controls at 12 weeks of age (Fig. 2E and F). Replacement of the AR in bone marrow PCs of GlobalARKO mice restored serum leptin levels to WT control levels whilst serum adiponectin remained elevated in PC-AR Gene Replacement mice $(P<0.001)$ (Fig. $2 \mathrm{E}$ and F). Fasting serum NEFA levels were unaffected in Global-ARKOs but were increased in PC-AR Gene Replacements compared to both WT and Global-ARKO controls $(P<0.05)$ (Table 2). Fasting serum glycerol levels were increased in Global-ARKOs and although the mean value was also higher in PC-AR Gene Replacements compared to WT controls, this was not statistically significant (Table 2). In contrast, the fasting serum levels of total triglycerides were unaffected in GlobalARKO and PC-AR Gene Replacement males (Table 2). 
A

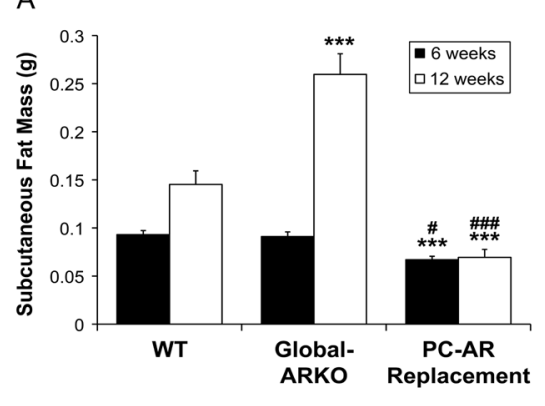

C
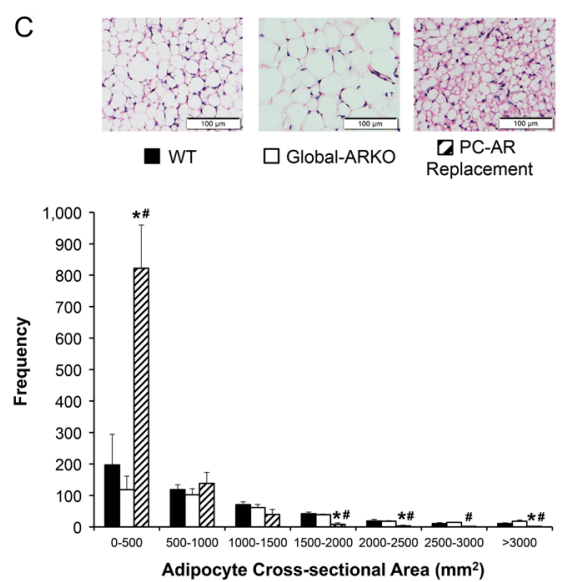

Adipocyte Cross-sectional Area $\left(\mathrm{mm}^{2}\right)$
B

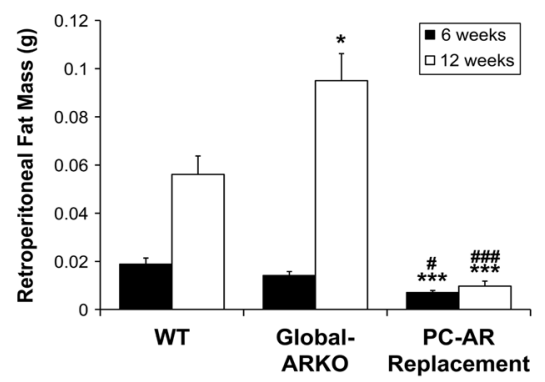

D
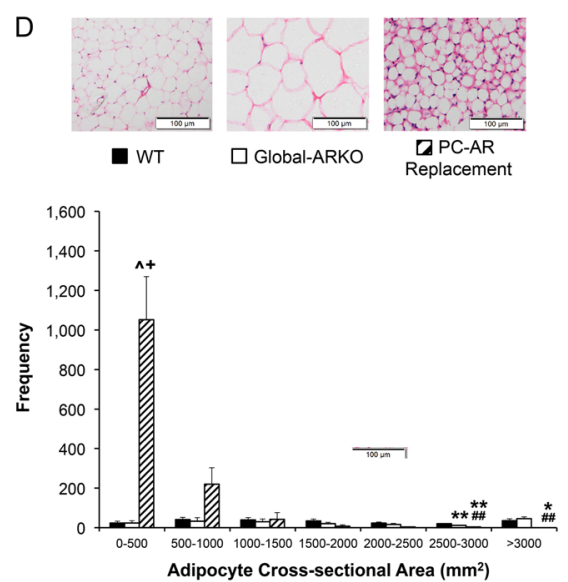

237:1

Figure 2

(A) Subcutaneous WAT and (B) retroperitoneal VAT mass in wild-type (WT), Global-ARKO and PC-AR Gene Replacement males at 6 and 12 weeks of age. Adipocyte cross-sectional area distribution in (C) subcutaneous and (D) peri-renal visceral fat at 12 weeks of age. Panels above graphs are representative images of adipocytes in WT, Global-ARKO and PC-AR Gene Replacements at 12 weeks of age, haematoxylin and eosin stain ( $\times 20)$. Serum (E) adiponectin and (F) leptin in WT, Global-ARKO and PC-AR Gene Replacements at 12 weeks of age. Values are mean +S.E.; for fat mass: $n=7-12 / g r o u p$ for 6 weeks; $n=11-18 /$ group for 12 weeks; for adipocyte analyses: $n=4-6 /$ group, 4 fields counted per section ( $>300$ adipocytes for WT); for serum analyses: $\mathrm{n}=10-14 /$ group. $* P<0.05, * * P<0.01, * * * P<0.001$ vs $W T,+P=0.05, \# P<0.05, \# P<0.01, \# \# P<0.001$ vs Global-ARKO within age group.

\section{BAT and hind-limb muscle mass of PC-AR Gene Replacement males}

BAT mass was decreased in PC-AR Gene Replacements compared to WT and Global-ARKO littermates at 12 weeks of age (Table 1); however, ANCOVA analysis indicated that this decrease in BAT mass was a function of their lower body weight and not due to their genotype. Similarly, the expression of genes known to be important in BAT metabolism, namely Ppara (peroxisome proliferatoractivated receptor alpha), Ppary (peroxisome proliferatoractivated receptor gamma), Ucp1 (uncoupling factor 1) and $A d r 3 b$ (adrenoreceptor beta 3 ) were unaffected in BAT of Global-ARKOs and PC-AR Gene Replacements (Supplementary Table 3). Consistent with our previous observations in Global-ARKO males (MacLean et al. 2008), the mass of the hind-limb muscles, gastrocnemius (Gast), extensor digitorum longus (EDL) and soleus (Sol), were decreased compared to WT (Table 1). Gast, EDL and Sol mass were further decreased in the PC-AR Gene Replacements compared to Global-ARKOs at 12 weeks

\begin{tabular}{|lr|}
\hline http://joe.endocrinology-journals.org & ( 2018 Society for Endocrinology \\
https://doi.org/10.1530/JOE-17-0656 & Published by Bioscientifica Ltd. \\
Printed in Great Britain
\end{tabular}
Printed in Great Britain of age (Table 1); however, only the mass of the Gast remained statistically significant following correction for body weight by ANCOVA with genotype accounting for $29 \%$ of the effect on Gast mass $(P<0.01)$.

\section{Gene expression in WAT and VAT of PC-AR Gene Replacement males}

To further characterise adipocyte homeostasis in the subcutaneous WAT and retroperitoneal VAT depots of the PC-AR Gene Replacements, we determined the expression levels of a number of genes that are known to be important in adipogenesis, lipogenesis, lipolysis, fatty acid metabolism, inflammation and energy balance and regulation. In retroperitoneal VAT, the expression of the PPAR $\alpha, S c d 1$ (stearoyl-coenzyme A desaturase 1), Cepbo, Acaca (acetyl-coenzyme A carboxylase alpha), Pnpla (patatin like phospholipase domain containing 2) and Glut 4 (solute carrier family 2 (facilitated glucose transporter), member 4) genes were upregulated in PC-AR 


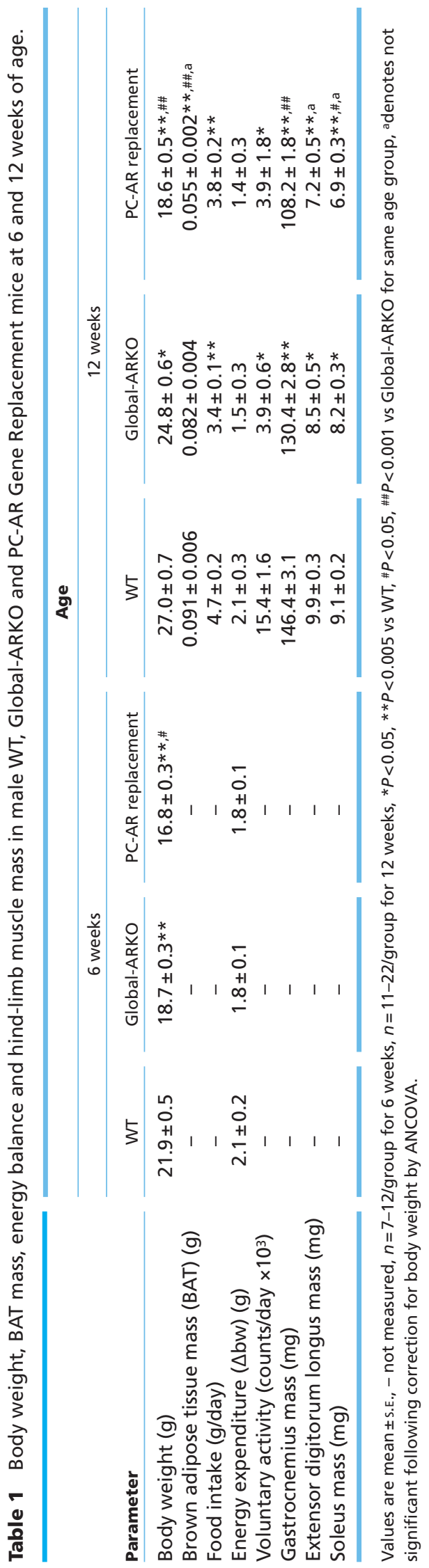

http://joe.endocrinology-journals.org https://doi.org/10.1530/JOE-17-0656 (c) 2018 Society for Endocrinology Published by Bioscientifica Ltd.
Printed in Great Britain
Gene Replacement males compared to WT $(P<0.05$, except for Cepba $P<0.01)$ and Global-ARKO $(P<0.05$, except for Cepba $P<0.01)$ controls at 12 weeks of age (Fig. 3A, B, C, D, E and F). The expression of PPAR $\alpha$ was also upregulated in subcutaneous WAT of PC-AR Gene Replacements compared to WT controls $(P=0.05)$ (Supplementary Table 3). Ucp1 gene expression was upregulated in subcutaneous WAT of Global-ARKOs and PC-AR Gene Replacements compared to WT controls $(P<0.05)$; however, there was no difference in $U c p 1$ gene expression between Global-ARKOs and PC-AR Gene Replacements (Supplementary Table 3).

\section{Whole-body insulin sensitivity and glucose metabolism of PC-AR Gene Replacement males}

To determine the effect of the marked decrease in subcutaneous WAT and retroperitoneal VAT mass in the PC-AR Gene Replacements on their metabolic profile, the euglycaemic/hyperinsulinaemic clamp technique was performed. There was no difference in plasma glucose or insulin between the WT, Global-ARKO or PC-AR Gene Replacements in either in the basal or insulin-stimulated state (Supplementary Table 4). Steady state was reached at 90,100 and $110 \mathrm{~min}$ following commencement of the euglycaemic/hyperinsulinaemic clamp as evidenced by a constant specific activity (dpm/ $\mu \mathrm{mol}$ ) across the three genotypes (data not shown). PC-AR Gene Replacement mice had an increased rate of glucose disappearance compared to WT $(P<0.05)$ (Fig. 4A). The calculated endogenous glucose production did not differ between the PC-AR Gene Replacement, WT and Global-ARKOs (Supplementary Table 4). Tissue-specific glucose uptake analyses indicate that the predominant site of glucose uptake in the PC-AR Gene Replacement mice is subcutaneous WAT $(P<0.01)$ and retroperitoneal VAT $(P<0.05)$ (Fig. 4B and C). Glucose uptake was unaltered in BAT (Fig. 4D) or the hind-limb muscles, including the Gast, EDL and Sol (data not shown).

\section{Bone marrow adiposity of PC-AR Gene Replacement males}

Bone marrow adiposity was increased in Global-ARKOs as evidenced by an increase in adipocyte cross-sectional area within the bone marrow cavity of the femur compared to WT controls $(P<0.05)$, which was restored to WT levels in PC-AR Gene Replacements (Fig. 5A). Consistent with the increased bone marrow adiposity in the GlobalARKOs was a decrease in the expression of the osteogenic 
Table 2 Serum lipids in WT, Global-ARKO and PC-AR Gene Replacement mice at 12 weeks of age.

\begin{tabular}{|c|c|c|c|}
\hline & \multicolumn{3}{|c|}{12 weeks } \\
\hline & WT & Global-ARKO & PC-AR replacement \\
\hline Total triglyceride $(\mathrm{mg} / \mathrm{mL})$ & $0.76 \pm 0.11$ & $0.66 \pm 0.04$ & $0.77 \pm 0.15$ \\
\hline Non-esterified fatty acids (mEq/L) & $1.00 \pm 0.06$ & $1.46 \pm 0.15$ & $2.24 \pm 0.45^{*}$ \\
\hline Glycerol (mg/mL) & $0.37 \pm 0.04$ & $0.61 \pm 0.07 *$ & $1.08 \pm 0.31$ \\
\hline
\end{tabular}

Values are mean \pm s.E., $n=5-17 /$ group, ${ }^{*} P<0.05$ vs WT.

transcription factor, Runx2, which was also normalised to WT levels in the PC-AR Gene Replacement mice (Fig. 5B).

\section{Osteokine gene expression}

The expression of the osteokine genes known to regulate fat metabolism, namely osteocalcin $(B g p)$ and osteoprotegerin $(\mathrm{Opg})$ did not differ in whole bone including bone marrow of PC-AR Gene Replacement males compared to Global-ARKO controls at 12 weeks of age (Supplementary Table 5).

\section{Discussion}

There is substantial evidence from studies in both humans and rodents indicating that androgens negatively regulate fat mass; yet, the mechanisms are not fully understood. Data from our own group and others using Global-ARKO mouse models have clearly shown that the action of androgens to negatively regulate fat mass in males is mediated, at least in part, via the AR (Fan et al. 2005, Lin et al. 2005, Rana et al. 2011). The absence of increased adiposity in the adipocyte-specific ARKO mouse models, however, suggest that the major target of androgen action to negatively regulate fat accumulation is mediated via the AR in another target tissue (Yu et al. 2008, McInnes et al. 2012). We now provide evidence for an important action of androgens via the $\mathrm{AR}$ in bone marrow mesenchymal PCs to negatively regulate subcutaneous WAT and retroperitoneal VAT accumulation and to improve metabolism in male mice. We achieved this by generating a unique mouse model in which the AR is specifically replaced in the bone marrow mesenchymal PCs of Global-ARKO mice. We confirmed AR transgene expression in whole bone and bone marrow of PC-AR
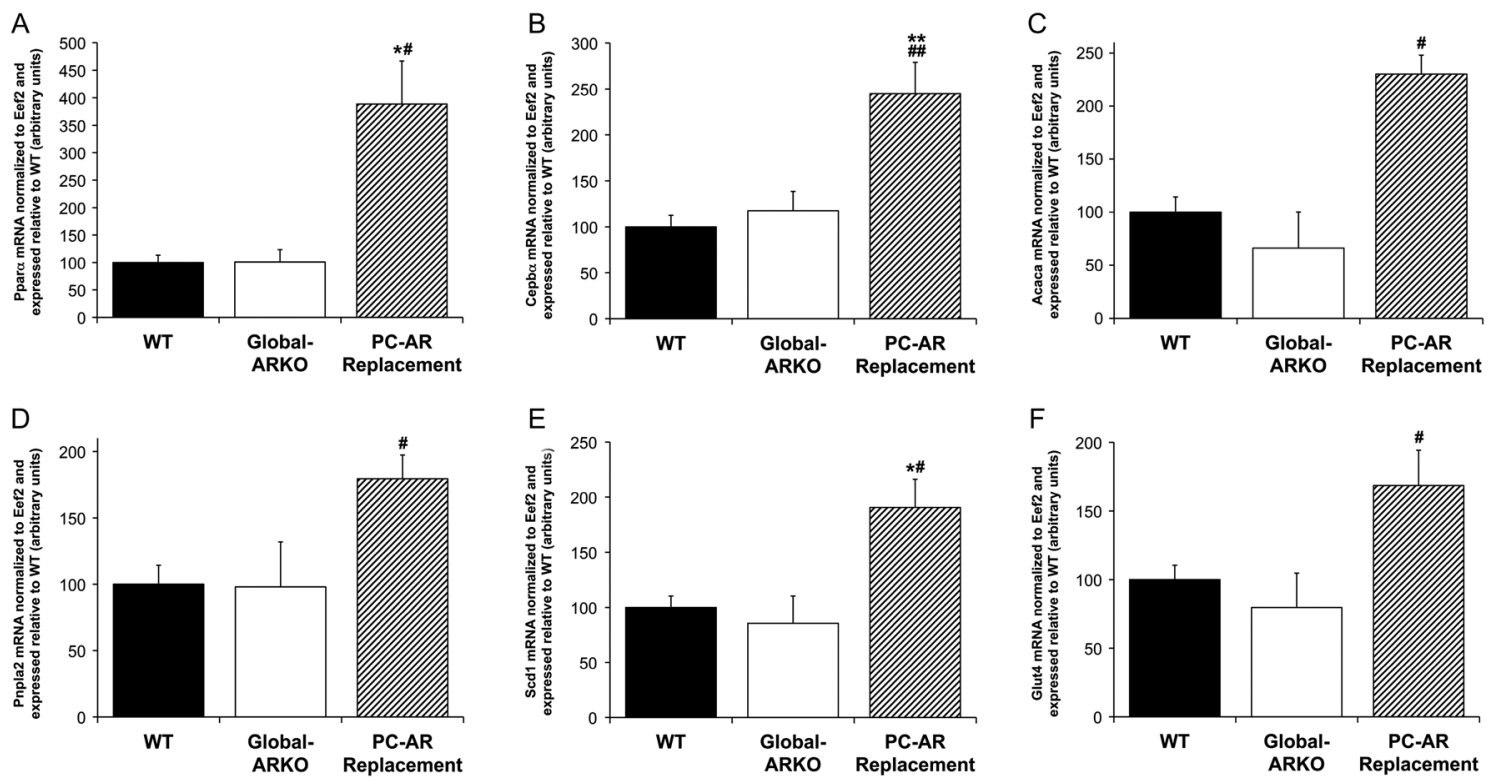

\section{Figure 3}

mRNA levels of genes expressed in retroperitoneal VAT of wild-type (WT), Global-ARKO and PC-AR Gene Replacement males at 12 weeks of age. (A) peroxisome proliferator-activated receptor alpha (Ppar $\alpha)$, (B) cyclic AMP responsive element-binding protein 1 (Cebp $\alpha)$ (C) acetyl-coenzyme A carboxylase alpha (Acaca), (D) patatin like phospholipase domain containing 2 (Pnpla2), (E) stearoyl-coenzyme A desaturase 1 (Scd1) and (F) solute carrier family 2 (facilitated glucose transporter) member 4 (Glut4). Values are mean + S.E., $n=6-9$ /group. $* P<0.05, * * P<0.001$ vs WT, ${ }^{*} P<0.05$, \#\#P<0.01 vs Global-ARKO. 

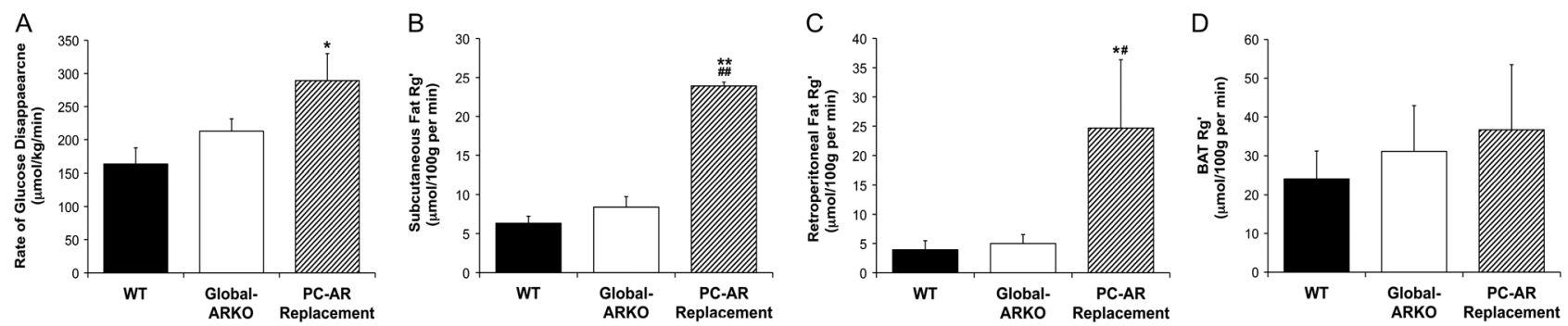

Figure 4

Euglycaemic/hyperinsulinaemic clamp studies in wild-type (WT), Global-ARKO and PC-AR Gene Replacement males at 12 weeks of age. (A) rate of glucose disappearance. Glucose uptake ( $\left.\mathrm{Rg}^{\prime}\right)$ into (B) subcutaneous WAT, (C) retroperitoneal VAT and (D) BAT under insulin-stimulated conditions. Values are mean +S.E., $n=4-6 /$ group. ${ }^{*} P<0.05,{ }^{* *} P<0.001$ vs $W T, " P<0.05, \# P<0.001$ vs Global-ARKO within age group.

Gene Replacement mice to the same level observed for endogenous AR expression in WT, whilst as expected, endogenous AR gene expression was undetectable in Global-ARKO and PC-AR Gene Replacement mice. It should be noted however, that since mesenchymal PCs represent only $0.1 \%$ of the population of cells within bone marrow, it is difficult to precisely determine the level of transgene AR mRNA in these cells. It is therefore conceivable that the level of transgene AR mRNA may be overexpressed in bone marrow PCs of PC-AR Gene Replacements compared to endogenous AR in WT bone marrow PCs. Importantly, AR transgene expression was absent in subcutaneous WAT, retroperitoneal VAT and BAT fat pads of PC-AR Gene Replacements. The strength of this unique PC-AR Gene Replacement model is the selective targeting of androgen signalling via expression of the AR specifically in PCs residing in the bone marrow with the AR remaining deleted in all other tissues. Further, a novel aspect of our PC-AR Gene Replacement model is the ability to evaluate the consequences of changes in body composition in vivo that are not mediated by hormone administration, providing an excellent means by which to study obesity-related pathologies.

We have previously shown that global deletion of the AR in Global-ARKO mice results in increased subcutaneous WAT and retroperitoneal VAT mass
(Rana et al. 2011). We now show that replacement of the AR in bone marrow PCs of Global-ARKO mice in PC-AR Gene Replacements completely attenuates their increased fat mass with subcutaneous WAT and retroperitoneal VAT depots resetting to below the normal levels seen in WT littermates by 12 weeks of age. This action of androgens via the AR to decrease fat mass can be attributed to an action on bone marrow mesenchymal PCs, including osteoprogenitors, as replacement of the AR at a later stage of osteoblast development in mature osteoblasts (mOBL-AR Gene Replacements) had no effect on subcutaneous WAT or retroperitoneal VAT mass. Unexpectedly, the marked decrease in fat mass of the PC-AR Gene Replacements occurred in the absence of any obvious changes in food consumption, energy expenditure or voluntary activity compared to Global-ARKO controls. Additional, more precise analyses of energy balance such as measurement of resting energy expenditure by calorimetry and energy absorption in the faeces are therefore warranted.

The increased fat mass in the absence of the AR in Global-ARKO males is associated with an increase in the number of large adipocytes, hyperleptinaemia and hyper adiponectinaemia whilst insulin resistance is unaffected (Rana et al. 2011). Replacement of the AR in bone marrow PCs of Global-ARKOs resulted in an increase in the number of smaller adipocytes and a decrease in the
A

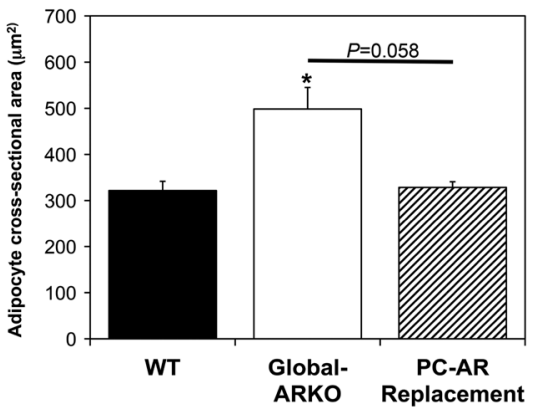

B

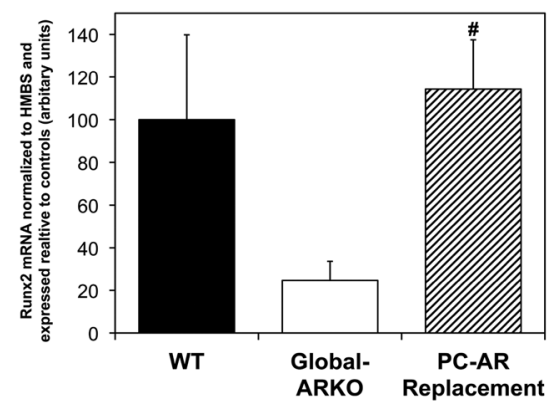

Figure 5

(A) Average adipocyte cross-sectional area within bone marrow and (B) Runx2 mRNA levels in whole bone in wild-type (WT), Global-ARKO and PC-AR Gene Replacement males at 12 weeks of age. Values are mean +5.E., $n=4-5 /$ group for adipocyte analysis, $n=8-10$ for Runx2 mRNA analysis. ${ }^{*} P<0.05$ vs WT, ${ }^{*} P<0.05$ vs Global-ARKO. http://joe.endocrinology-journals.org https://doi.org/10.1530/JOE-17-0656 (c) 2018 Society for Endocrinology Published by Bioscientifica Ltd. Printed in Great Britain 
number of large adipocytes in PC-AR Gene Replacements compared to both WT and Global-ARKOs, consistent with increased adipocyte hyperplasia and decreased adipocyte hypertrophy. The increase in adipocyte hyperplasia in PC-AR Gene Replacements was accompanied by an increase in the expression of one of the key transcription factors involved in adipogenesis, Cebp $\alpha$, in retroperitoneal VAT. It has previously been shown in rodents that relative to large adipocytes, smaller adipocytes have higher rates of glucose oxidation in the presence of insulin (Olefsky 1976), suggesting that the smaller adipocytes in the PC-AR Gene Replacements may be more metabolically active. Consistent with notion, in the retroperitoneal VAT of PC-AR Gene Replacements, we observed increases in the expression of genes involved in fatty acid metabolism (Ppara and Scd1), lipogenesis (Acaca) and lipolysis (Pnpla2) as well as increased serum levels of NEFA, which in the fasting state, arise almost entirely from hydrolysis of triacylglycerol within the adipocyte (Karpe et al. 2011). In line with their apparent healthier metabolic profile and lean phenotype, PC-AR Gene Replacements had normal serum levels of leptin, whilst serum levels of adiponectin remained elevated (Silha et al. 2003). Euglycaemic/ hyperinsulinaemic clamp analyses revealed that PC-AR Gene Replacement mice had a higher rate of glucose disappearance compared to WT, indicating an increase in whole-body insulin sensitivity with increased glucose uptake into subcutaneous WAT and retroperitoneal VAT depots, whilst glucose uptake was not altered in BAT or the hind-limb muscles of PC-AR Gene Replacements. Consistent with the increased glucose uptake into retroperitoneal VAT was an increase in the expression of the glucose transporter gene, Glut4.

Of interest, whilst the effect of replacing the AR in the bone marrow PCs of Global-ARKO mice to decrease fat accumulation was highly significant for both WAT and VAT depots, this effect was more marked in retroperitoneal VAT than subcutaneous WAT as implied by the magnitude of the decrease in fat mass ( $52 \%$ WAT vs 83\% VAT compared to WT) and the substantially higher number of adipogenenic and metabolic genes regulated in VAT compared to WAT. This is consistent with the higher rates of energy, glucose and lipid metabolism documented for retroperitoneal VAT that inguinal WAT in rodents (Sackmann-Sala et al. 2012). It is therefore likely that the marked decrease in VAT, rather than WAT, in the PC-AR Gene Replacements is responsible for their improved metabolic profile, particularly given it is well established that increased VAT accumulation is associated with metabolic disease (Lee et al. 2013).
The average cross-sectional area of adipocytes within the bone marrow was increased in Global-ARKOs. Replacement of the AR in bone marrow PCs of GlobalARKOs in PC-AR Gene Replacement mice restored the size and number of adipocytes within the bone marrow to WT control levels. These data are consistent with previous observations in human bone marrow PCs in vitro of an action of androgens to inhibit the differentiation of bone marrow mesenchymal PCs into adipocytes via an AR-dependent pathway (Gupta et al. 2008, Benvenuti et al. 2012). Furthermore, it has also been reported that adipogenesis is increased and osteogenesis is decreased in PCs derived from bone marrow of Global-ARKO mice in vitro (Huang et al. 2013) whilst conversely, bone marrow adipogenesis is reduced in Col3.6AR-tg mice (Semirale et al. 2011). Consistent with increased osteogenesis within the bone marrow of the PC-AR Gene Replacement was the upregulation of Runx2 expression, a transcription factor critical for osteoblast differentiation, in addition to our previous report of increased trabecular bone formation in PC-AR Gene Replacement males (Russell et al. 2015). These data have important implications for hypogonadal patients as compared to the other fat depots, bone marrow adipose tissue (BMAT) is significantly associated with skeletal health. Although studies on the function of BMAT is limited, it is clear that increased BMAT is associated with decreased bone mineral density in ageing and following the menopause (Hardouin et al. 2016, Suchacki et al. 2016).

The precise mechanism by which androgens exert their effects via the AR in bone marrow PCs to negatively regulate fat mass remains to be determined. The normalisation of bone marrow adipogenesis observed in the PC-AR Gene Replacement mice is consistent with a role for androgens acting via the AR to divert their differentiation away from the adipocyte lineage towards the bone lineage. Whilst AR transgene expression was undetectable in WAT and VAT of adult PC-AR Gene Replacements by Q-PCR, this does not rule out the presence of the AR transgene at very low levels in the fat of adult PC-AR Gene Replacements or the possible migration of the bone marrow PCs to adipose tissue pre-natally to influence fat deposition in these mice. Since it has been shown that the migration of mesenchymal precursor cells from the bone marrow into peripheral tissues is extremely low in irradiated mice (Tomiyama et al. 2008), together with the recent identification of osteokines that can regulate aspects of energy metabolism, an alternative action of androgens via the AR within bone marrow PCs, therefore, may be to regulate the secretion of osteokines, which are then 
released into the circulation to negatively regulate fat mass. To investigate this possibility, we measured the gene expression levels of the known osteokines, osteocalcin and osteoprotegerin in whole bone and bone marrow of PC-AR Gene Replacements, which were determined not to differ between PC-AR Gene Replacements and Global-ARKO controls. Unfortunately, the large volume of serum required for the accurate measurement of undercarboxylated osteocalcin, the form of osteocalcin responsible for mediating its metabolic effects, precluded its measurement in the current study. Whilst these findings do not rule out the possible involvement of these osteokines in mediating the decreased fat mass in the PC-AR Gene Replacements, it suggests that they are unlikely candidates. Further investigation into the possibility of circulating factor/s being responsible for mediating the negative regulation of fat mass in the PC-AR Gene Replacement mice is therefore warranted.

It is likely that the actions of the AR in bone marrow PCs to markedly reduce subcutaneous WAT and retroperitoneal VAT accumulation in the PC-AR Gene Replacements originate during development as expression of the AR in bone marrow PCs occurs when the type $1 \mathrm{a} 1$ collagen $3.6 \mathrm{~kb}$ promoter is expressed from embryonic day 8 (Lengner et al. 2006). Importantly, however, we have previously shown that the actions of the AR in bone marrow PCs to decrease fat mass also plays a significant role to reverse the increase in fat accumulation that occurs following orchidectomy in both adult male and female PC-ARtg mice overexpressing the AR in bone marrow PCs (Wiren et al. 2011). These data demonstrate that body composition remains linked to bone marrow PCs in the adult, indicating a potential therapeutic benefit of targeting these cells or the bonederived factor/s secreted by these cells for the treatment of obesity in both children and adults.

It is well established that global deletion of the AR in male mice results in decreased hind-limb muscle mass, with this positive regulation of hind-limb muscle mass by androgens being mediated somewhat surprisingly by the AR in the brain and not via the AR in satellite cells, myoblasts or myocytes (Chambon et al. 2010, Dubois et al. 2014, Rana et al. 2016, Davey et al. 2017). Of significant interest in the present study was the observation that restoration of AR signalling in bone marrow PCs resulted in a further reduction in the mass of the Gast hind-limb muscle in the PC-AR Gene Replacement mice, following correction for body weight. These data are difficult to reconcile, given that androgens promote the myogenic differentiation of bone marrow PCs (Singh et al. 2003). Perhaps this action of androgens requires the presence of
AR signalling in other target tissues, which is absent in the PC-AR Gene Replacements. Nonetheless these data are intriguing and require further investigation.

This study provides significant new data identifying a role of androgens acting via the AR in bone marrow PCs to negatively regulate fat mass, however it is not without its limitations. The marked decrease in subcutaneous WAT and retroperitoneal VAT mass in PC-AR Gene Replacement mice compared to WT mice is a significant finding that warrants further investigation. It is possible that this is due to either an over-expression or an increased activation of the AR transgene in the bone marrow PCs of the PC-AR Gene replacement mice or could be the result of the AR only being expressed in bone marrow PCs, whilst it is absent in all other tissues. DXA analysis was not available for this study but could provide valuable information relating to wholebody composition, particularly considering the low body weight of the PC-AR Gene Replacement mice. Furthermore, characterisation of the PC-AR Gene Replacement mice at an older age is also likely to generate significant data as AR signalling has been reported to be important in the development of late-onset obesity (Fan et al. 2005, Lin et al. 2005, Rana etal. 2011). Lastly, whilst we have determined that serum testosterone levels in the PC-AR Gene Replacement mice do not differ significantly from WT mice, insufficient serum volume precluded the analysis of other metabolites such as oestradiol, which could prove to be informative.

In conclusion, our data provide the first evidence for an action of androgens via the AR in bone marrow PCs to negatively regulate WAT and VAT fat accumulation and improve metabolic function. These findings in our unique PC-AR Gene Replacement mouse model provide a significant advancement in our understanding of how androgens acting via the AR negatively regulate fat mass and is the first, but crucial step towards identifying potential therapeutic targets for the treatment of obesity.

\section{Supplementary data}

This is linked to the online version of the paper at https://doi.org/10.1530/ JOE-17-0656.

\section{Declaration of interest}

The authors declare that there is no conflict of interest that could be perceived as prejudicing the impartiality of the research reported.

\section{Funding}

The work was supported by the National Health and Medical Research Council of Australia (Project Grant 566503), The University of Melbourne 
Grant Support Scheme, The Sir Edward Dunlop Medical Research Foundation, The Austin Health Research Foundation and a Les and Eva Erdi Research Grant.

\section{Author contribution statement}

Authors' roles: Study design: R A D and J D Z; Study conduct and data collection: P K R, S M, R A D, M V C, B C F, E S M; Data analysis: P K R and $R A D ;$ Drafting manuscript: $R A D$ and $P K R$; Revising manuscript: $S A, B C F$, $K M$ W, P K R, J D Z and R A D; Approval of final version of the manuscript: all authors.

\section{References}

Benvenuti S, Cellai I, Luciani P, Deledda C, Saccardi R, Mazzanti B, Dal Pozzo S, Serio M \& Peri A 2012 Androgens and estrogens prevent rosiglitazone-induced adipogenesis in human mesenchymal stem cells. Journal of Endocrinological Investigation 35 365-371. (https://doi. org/10.3275/7739)

Bhasin S, Storer TW, Berman N, Yarasheski KE, Clevenger B, Phillips J, Lee WP, Bunnell TJ \& Casaburi R 1997 Testosterone replacement increases fat-free mass and muscle size in hypogonadal men. Journal of Clinical Endocrinology and Metabolism 82 407-413. (https://doi. org/10.1210/jcem.82.2.3733)

Bhasin S, Woodhouse L, Casaburi R, Singh AB, Bhasin D, Berman N, Chen X, Yarasheski KE, Magliano L, Dzekov C, et al. 2001 Testosterone dose-response relationships in healthy young men. American Journal of Physiology: Endocrinology and Metabolism 281 E1172-E1181. (https:// doi.org/10.1152/ajpendo.2001.281.6.E1172)

Chambon C, Duteil D, Vignaud A, Ferry A, Messaddeq N, Malivindi R, Kato S, Chambon P \& Metzger D 2010 Myocytic androgen receptor controls the strength but not the mass of limb muscles. PNAS $\mathbf{1 0 7}$ 14327-14332. (https://doi.org/10.1073/pnas.1009536107)

Crossno JT Jr, Majka SM, Grazia T, Gill RG \& Klemm DJ 2006 Rosiglitazone promotes development of a novel adipocyte population from bone marrow-derived circulating progenitor cells. Journal of Clinical Investigation 116 3220-3228. (https://doi.org/10.1172/ JCI28510)

Cui XB, Luan JN \& Chen SY 2015 RGC-32 deficiency protects against hepatic steatosis by reducing lipogenesis. Journal of Biological Chemistry 290 20387-20395. (https://doi.org/10.1074/jbc. M114.630186)

Davey RA \& MacLean HE 2006 Current and future approaches using genetically modified mice in endocrine research. American Journal of Physiology: Endocrinology and Metabolism 291 E429-E438. (https://doi. org/10.1152/ajpendo.00124.2006)

Davey RA, Clarke MV, Russell PK, Rana K, Seto J, Roeszler KN, How JMY, Chia LY, North K \& Zajac JD 2017 Androgen action via the androgen receptor in neurons within the brain positively regulates muscle mass in male mice. Endocrinology 158 3684-3695. (https://doi.org/10.1210/ en.2017-00470)

Dubois V, Laurent MR, Sinnesael M, Cielen N, Helsen C, Clinckemalie L, Spans L, Gayan-Ramirez G, Deldicque L, Hespel P, et al. 2014 A satellite cell-specific knockout of the androgen receptor reveals myostatin as a direct androgen target in skeletal muscle. FASEB Journal 28 2979-2994. (https://doi.org/10.1096/fj.14-249748)

Dubois V, Laurent MR, Jardi F, Antonio L, Lemaire K, Goyvaerts L, Deldicque L, Carmeliet G, Decallonne B, Vanderschueren D, et al. 2016 Androgen deficiency exacerbates high-fat diet-induced metabolic alterations in male mice. Endocrinology 157 648-665. (https://doi.org/10.1210/en.2015-1713)

Fam BC, Sgambellone R, Ruan Z, Proietto J \& Andrikopoulos S 2015 Contribution of the hypothalamus and gut to weight gain susceptibility and resistance in mice. Journal of Endocrinology $\mathbf{2 2 5}$ 191-204. (https://doi.org/10.1530/JOE-15-0131)

Fan W, Yanase T, Nomura M, Okabe T, Goto K, Sato T, Kawano H, Kato S \& Nawata H 2005 Androgen receptor null male mice develop lateonset obesity caused by decreased energy expenditure and lipolytic activity but show normal insulin sensitivity with high adiponectin secretion. Diabetes 54 1000-1008. (https://doi.org/10.2337/ diabetes.54.4.1000)

Gupta V, Bhasin S, Guo W, Singh R, Miki R, Chauhan P, Choong K, Tchkonia T, Lebrasseur NK, Flanagan JN, et al. 2008 Effects of dihydrotestosterone on differentiation and proliferation of human mesenchymal stem cells and preadipocytes. Molecular and Cellular Endocrinology 296 32-40. (https://doi.org/10.1016/j.mce.2008.08.019)

Hamilton EJ, Gianatti E, Strauss BJ, Wentworth J, Lim-Joon D, Bolton D, Zajac JD \& Grossmann M 2011 Increase in visceral and subcutaneous abdominal fat in men with prostate cancer treated with androgen deprivation therapy. Clinical Endocrinology 74 377-383. (https://doi. org/10.1111/j.1365-2265.2010.03942.x)

Hardouin P, Rharass T \& Lucas S 2016 Bone marrow adipose tissue: to be or not to be a typical adipose tissue? Frontiers in Endocrinology 785.

Huang CK, Lai KP, Luo J, Tsai MY, Kang HY, Chen Y, Lee SO \& Chang C 2013 Loss of androgen receptor promotes adipogenesis but suppresses osteogenesis in bone marrow stromal cells. Stem Cell Research $\mathbf{1 1}$ 938-950. (https://doi.org/10.1016/j.scr.2013.06.001)

Ilich JZ, Kelly OJ, Inglis JE, Panton LB, Duque G \& Ormsbee MJ 2014 Interrelationship among muscle, fat, and bone: connecting the dots on cellular, hormonal, and whole body levels. Ageing Research Reviews 15 51-60. (https://doi.org/10.1016/j.arr.2014.02.007)

Jo J, Gavrilova O, Pack S, Jou W, Mullen S, Sumner AE, Cushman SW \& Periwal V 2009 Hypertrophy and/or hyperplasia: dynamics of adipose tissue growth. PLOS Computational Biology 5 e1000324. (https://doi. org/10.1371/journal.pcbi.1000324)

Karpe F, Dickmann JR \& Frayn KN 2011 Fatty acids, obesity, and insulin resistance: time for a reevaluation. Diabetes 60 2441-2449. (https:// doi.org/10.2337/db11-0425)

Kouadjo KE, Nishida Y, Cadrin-Girard JF, Yoshioka M \& St-Amand J 2007 Housekeeping and tissue-specific genes in mouse tissues. BMC Genomics 8 127. (https://doi.org/10.1186/1471-2164-8-127)

Lamont BJ, Visinoni S, Fam BC, Kebede M, Weinrich B, Papapostolou S, Massinet H, Proietto J, Favaloro J \& Andrikopoulos S 2006 Expression of human fructose-1,6-bisphosphatase in the liver of transgenic mice results in increased glycerol gluconeogenesis. Endocrinology 147 2764-2772. (https://doi.org/10.1210/en.2005-1498)

Lee NK \& Karsenty G 2008 Reciprocal regulation of bone and energy metabolism. Journal of Musculoskeletal and Neuronal Interactions 8351 .

Lee MJ, Wu Y \& Fried SK 2013 Adipose tissue heterogeneity: implication of depot differences in adipose tissue for obesity complications. Molecular Aspects of Medicine 34 1-11. (https://doi.org/10.1016/j. mam.2012.10.001)

Lengner CJ, Steinman HA, Gagnon J, Smith TW, Henderson JE, Kream BE, Stein GS, Lian JB \& Jones SN 2006 Osteoblast differentiation and skeletal development are regulated by Mdm2-p53 signaling. Journal of Cell Biology 172 909-921. (https://doi.org/10.1083/jcb.200508130)

Lin HY, Xu Q, Yeh S, Wang RS, Sparks JD \& Chang C 2005 Insulin and leptin resistance with hyperleptinemia in mice lacking androgen receptor. Diabetes 54 1717-1725. (https://doi.org/10.2337/ diabetes.54.6.1717)

MacLean HE, Chiu WS, Notini AJ, Axell AM, Davey RA, McManus JF, Ma C, Plant DR, Lynch GS \& Zajac JD 2008 Impaired skeletal muscle development and function in male, but not female, genomic androgen receptor knockout mice. FASEB Journal 22 2676-2689. (https://doi.org/10.1096/fj.08-105726)

MacLean HE, Moore AJ, Sastra SA, Morris HA, Ghasem-Zadeh A, Rana K, Axell AM, Notini AJ, Handelsman DJ, Seeman E, et al. 2010 DNAbinding-dependent androgen receptor signaling contributes to gender differences and has physiological actions in males and females. http://joe.endocrinology-journals.org

https://doi.org/10.1530/JOE-17-0656
() 2018 Society for Endocrinology Published by Bioscientifica Ltd. Printed in Great Britain 
Journal of Endocrinology 206 93-103. (https://doi.org/10.1677/JOE-100026)

Majka SM, Fox KE, Psilas JC, Helm KM, Childs CR, Acosta AS, Janssen RC, Friedman JE, Woessner BT, Shade TR, et al. 2010 De novo generation of white adipocytes from the myeloid lineage via mesenchymal intermediates is age, adipose depot, and gender specific. PNAS $\mathbf{1 0 7}$ 14781-14786. (https://doi.org/10.1073/pnas.1003512107)

McInnes KJ, Smith LB, Hunger NI, Saunders PT, Andrew R \& Walker BR 2012 Deletion of the androgen receptor in adipose tissue in male mice elevates retinol binding protein 4 and reveals independent effects on visceral fat mass and on glucose homeostasis. Diabetes 61 1072-1081. (https://doi.org/10.2337/db11-1136)

Notini AJ, Davey RA, McManus JF, Bate KL \& Zajac JD 2005 Genomic actions of the androgen receptor are required for normal male sexual differentiation in a mouse model. Journal of Molecular Endocrinology 35 547-555. (https://doi.org/10.1677/jme.1.01884)

Olefsky JM 1976 The effects of spontaneous obesity on insulin binding, glucose transport, and glucose oxidation of isolated rat adipocytes. Journal of Clinical Investigation 57 842-851. (https://doi.org/10.1172/ JCI108360)

Pang TP, Clarke MV, Ghasem-Zadeh A, Lee NK, Davey RA \& MacLean HE 2012 A physiological role for androgen actions in the absence of androgen receptor DNA binding activity. Molecular and Cellular Endocrinology 348 189-197. (https://doi.org/10.1016/j. mce.2011.08.017)

Rana K, Fam BC, Clarke MV, Pang TP, Zajac JD \& MacLean HE 2011 Increased adiposity in DNA binding-dependent androgen receptor knockout male mice associated with decreased voluntary activity and not insulin resistance. American Journal of Physiology: Endocrinology and Metabolism 301 E767-E778. (https://doi.org/10.1152/ ajpendo.00584.2010)

Rana K, Chiu MW, Russell PK, Skinner JP, Lee NK, Fam BC, Zajac JD \& MacLean HE 2016 Muscle-specific androgen receptor deletion shows limited actions in myoblasts but not in myofibers in different muscles in vivo. Journal of Molecular Endocrinology 57 125-138. (https://doi. org/10.1530/JME-15-0320)

Rodeheffer MS, Birsoy K \& Friedman JM 2008 Identification of white adipocyte progenitor cells in vivo. Cell 135 240-249. (https://doi. org/10.1016/j.cell.2008.09.036)

Russell PK, Clarke MV, Skinner JP, Pang TP, Zajac JD \& Davey RA 2012 Identification of gene pathways altered by deletion of the androgen receptor specifically in mineralizing osteoblasts and osteocytes in mice. Journal of Molecular Endocrinology 49 1-10. (https://doi. org/10.1530/JME-12-0014)

Russell PK, Clarke MV, Cheong K, Anderson PH, Morris HA, Wiren KM, Zajac JD \& Davey RA 2015 Androgen receptor action in osteoblasts in male mice is dependent on their stage of maturation. Journal of Bone and Mineral Research 30 809-823. (https://doi.org/10.1002/jbmr.2413)

Sackmann-Sala L, Berryman DE, Munn RD, Lubbers ER \& Kopchick JJ 2012 Heterogeneity among white adipose tissue depots in male
C57BL/6J mice. Obesity 20 101-111. (https://doi.org/10.1038/ oby.2011.235)

Semirale AA, Zhang XW \& Wiren KM 2011 Body composition changes and inhibition of fat development in vivo implicates androgen in regulation of stem cell lineage allocation. Journal of Cellular Biochemistry 112 1773-1786. (https://doi.org/10.1002/jcb.23098)

Silha JV, Krsek M, Skrha JV, Sucharda P, Nyomba BL \& Murphy LJ 2003 Plasma resistin, adiponectin and leptin levels in lean and obese subjects: correlations with insulin resistance. European Journal of Endocrinology 149 331-335. (https://doi.org/10.1530/eje.0.1490331)

Singh R, Artaza JN, Taylor WE, Gonzalez-Cadavid NF \& Bhasin S 2003 Androgens stimulate myogenic differentiation and inhibit adipogenesis in C3H 10T1/2 pluripotent cells through an androgen receptor-mediated pathway. Endocrinology 144 5081-5088. (https:// doi.org/10.1210/en.2003-0741)

Stephens AS, Stephens SR \& Morrison NA 2011 Internal control genes for quantitative RT-PCR expression analysis in mouse osteoblasts, osteoclasts and macrophages. BMC Research Notes 4 410. (https://doi. org/10.1186/1756-0500-4-410)

Suchacki KJ, Cawthorn WP \& Rosen CJ 2016 Bone marrow adipose tissue: formation, function and regulation. Current Opinion in Pharmacology 28 50-56. (https://doi.org/10.1016/j.coph.2016.03.001)

Tomiyama K, Murase N, Stolz DB, Toyokawa H, O'Donnell DR, Smith DM, Dudas JR, Rubin JP \& Marra KG 2008 Characterization of transplanted green fluorescent protein+ bone marrow cells into adipose tissue. Stem Cells 26 330-338. (https://doi.org/10.1634/ stemcells.2007-0567)

Van Caenegem E, Wierckx K, Taes Y, Schreiner T, Vandewalle S, Toye K, Lapauw B, Kaufman JM \& T'Sjoen G 2015 Body composition, bone turnover, and bone mass in trans men during testosterone treatment: 1-year follow-up data from a prospective case-controlled study (ENIGI). European Journal of Endocrinology 172 163-171.

Wang C, Swerdloff RS, Iranmanesh A, Dobs A, Snyder PJ, Cunningham G, Matsumoto AM, Weber T \& Berman N 2000 Transdermal testosterone gel improves sexual function, mood, muscle strength, and body composition parameters in hypogonadal men. Journal of Clinical Endocrinology and Metabolism 85 2839-2853.

Wiren KM, Semirale AA, Zhang XW, Woo A, Tommasini SM, Price C, Schaffler MB \& Jepsen KJ 2008 Targeting of androgen receptor in bone reveals a lack of androgen anabolic action and inhibition of osteogenesis: a model for compartment-specific androgen action in the skeleton. Bone 43 440-451. (https://doi.org/10.1016/j.bone.2008.04.026)

Wiren KM, Hashimoto JG \& Zhang XW 2011 Stem cell activation in adults can reverse detrimental changes in body composition to reduce fat and increase lean mass in both sexes. Journal of Cellular Biochemistry 112 3638-3647. (https://doi.org/10.1002/jcb.23288)

Yu IC, Lin HY, Liu NC, Wang RS, Sparks JD, Yeh S \& Chang C 2008 Hyperleptinemia without obesity in male mice lacking androgen receptor in adipose tissue. Endocrinology 149 2361-2368. (https://doi. org/10.1210/en.2007-0516)

Received in final form 22 January 2018

Accepted 29 January 2018

Accepted Preprint published online 31 January 2018 http://joe.endocrinology-journals.org

https://doi.org/10.1530/JOE-17-0656 (c) 2018 Society for Endocrinology Published by Bioscientifica Ltd. Printed in Great Britain 